\title{
Polymorphism of the Serotonin Transporter Gene and the Peripheral 5-Hydroxytryptamine in Obstructive Sleep Apnea: What Do We Know and What are We Looking for? A Systematic Review of the Literature
}

This article was published in the following Dove Press journal: Nature and Science of Sleep

\author{
Anca Diana Maierean ${ }^{\mathrm{l}, *}$ \\ loana Roxana Bordea ${ }^{2 *}$ \\ Tudor Salagean ${ }^{3}$ \\ Reem Hanna (iD ${ }^{4,5}$ \\ Teodora Gabriela Alexescu (iD ${ }^{6}$ \\ Ana Chis' \\ Doina Adina Todea $\mathbb{I D}^{1, *}$ \\ 'Department of Pneumology, "luliu \\ Hatieganu" University of Medicine and \\ Pharmacy, Cluj-Napoca, Romania; \\ ${ }^{2}$ Department of Oral Rehabilitation, \\ "Iuliu Hatieganu" University of Medicine \\ and Pharmacy, Cluj-Napoca, Romania; \\ ${ }^{3}$ Department of Land Measurements and \\ Exact Sciences, University of Agricultural \\ Sciences and Veterinary Medicine, Cluj- \\ Napoca, Romania; ${ }^{4}$ Department of \\ Surgical Sciences and Integrated \\ Diagnostics, Laser Therapy Centre, \\ University of Genoa, Genoa, 16132, Italy; \\ ${ }^{5}$ Department of Oral Surgery, Dental \\ Institute, King's College Hospital NHS \\ Foundation Trust, London, SE5 9RS, UK; \\ ${ }^{6}$ Department of Internal Medicine, "Iuliu \\ Hatieganu" University of Medicine and \\ Pharmacy, Cluj-Napoca, Romania
}

*These authors contributed equally to this work

Correspondence: Tudor Salagean Email tudor.salagean@usamvcluj.roand

loana Roxana Bordea

Cluj-Napoca County, Gheorghe Lazar

Street, No. 4, Building D4, Ap 4,

Tel +4074491939l

Email roxana.bordea@ymail.com
Background: Obstructive sleep apnea (OSA) is a highly prevalent disease with substantial public health burden. In most of the cases, there is a genetic predisposition to OSA. Serotonin/T-HydroxyTriptamine (5-HT) plays a key role in ventilatory stimulation, while the polymorphism of the serotonin transporter gene (STG) leads to alterations in serotonin level, making it important in OSA.

Objective: To examine whether the 5-HydroxyTriptamine and the genetic predisposition influence the incidence and evolution of OSA, we reviewed randomized, controlled trials and observational studies on the selected topic. The secondary objective was to determine the metabolic effects of the circulating serotonin in other tissues (liver, pancreas, gut, brown adipose tissue, and white adipose tissue) and its role in the development of obesity.

Data Sources: A systematic review of English articles was performed based on PubMed and the Cochrane Library databases. Search filters included randomized controlled trial, controlled clinical trial, random allocation, double-blind method, and case-control studies and used the following keywords: Brain Serotonin OR Serotonin Transporter Gene Polymorphism OR Peripheral 5-HydroxyTryptamine AND Obstructive Sleep Apnea OR Sleep Disorder Breathing OR brain serotonin AND OSA OR serotonin transporter gene OR Peripheral 5-Hydroxytryptamine AND Sleep.

Study Eligibility Criteria: The inclusion criteria for the current review were previous diagnosis of OSA, age above 18 years, and articles including quantitative data about serotonin transporter gene or peripheral serotonin. Language and time criteria were added - English articles published in the last 15 years. Studies that were not included were reviews and case reports.

Study Appraisal and Synthesis Methods: In order to study the serotonin function, a literature research was conducted in the databases Pubmed and Cochrane Library. The following search terms were used: serotonin, 5-hydroxytryptamine, serotonin transporter gene. A critical appraisal of the included studies was performed with the NewcastleOttawa scale (NOS) and Delphi list.

Results: The search yielded 1210 articles, from which 43 were included. The included studies suggest that the two polymorphisms of serotonin transporter gene (5HTT) - variable number of tandem repeats (VNTR) and linked polymorphic region (LPR) - are strong candidates in the pathogenesis of OSA. The allele 10 of 5HTTVNTR and the long/long 
(L/L) allele genotype were associated with a higher prevalence of OSA and the L allele with a higher apnea-hypopnea index and a longer time during sleep with oxygen desaturation.

Limitations: The main limitation of the present study consists of heterogeneity of the information. Being a less studied subject, randomized trials are not widely available and most data were obtained from case-control trials. Moreover, the included material indirectly approached the subject by demonstrating the effects of serotoninergic system over the metabolism, the connection between serotonin and obesity, factors which are implied in the pathogenesis of OSA.

Conclusion and Implications of Key Findings: The two polymorphisms of serotonin gene can be considered important factors in the diagnosis and management of OSA.

Keywords: 5-HTTLPR, 5-HTTVNTR, sleep disorder breathing, obesity

\section{Introduction}

Obstructive sleep apnea (OSA) is a pathological condition characterized by repetitive upper airway collapse during sleep, either in the form of reduced airflow (hypopnea) or complete cessation of the airflow (apnea), events with a duration longer than 10 seconds and a drop in the oxygen saturation by at least 3\%. Obstructive events lead to hypoxemia and are usually terminated by a cortical arousal from sleep resulting in muscle activation and recovery of the airway patency. ${ }^{1,2}$ The specific symptomatology consists in loud snoring, arousals with a fragmented sleep, excessive daytime sleepiness, choking, gasping, or snorting. Sleep apnea syndrome is associated with symptoms of functional impairment, that can be life-threatening and are responsible for extreme daytime hypersomnolence, automobile accidents, and cardiovascular morbidity and mortality. ${ }^{3}$ OSA is a complex disease, resulting from multiple interacting genetic and environmental factors. Diagnosis is based on clinical symptoms, objective examination of the upper airway, imaging studies, and polysomnography (PSG), which is the gold standard. ${ }^{4,5}$

OSA is a heritable condition, with a genetic susceptibility. Also, there are other phenotypes that can occur and determine the disease, such as obesity, affected neurological control of the upper airway, modifications of the craniofacial structures, and disturbances of the circadian rhythm or sleep. ${ }^{6-8}$

In the last years, OSA has been considered a multifactorial disease. The main risk factors for OSA are obesity, impairment of the central control of ventilation, environmental influences, craniofacial morphology, and the polymorphisms of several genes. ${ }^{9-11}$

Various data from the literature have recently shown that the pathophysiology of OSA is complex and influenced by a number of factors. The genetic predisposition and the implication of serotoninergic system in the development of OSA open a multitude of diagnostic and therapeutic options. The serotonin transporter gene has two polymorphisms involved in OSA: 5-HTTVNTR and 5-HTTLPR. There are many genetic modifications. L/L genotype was more frequent in males, leading to an explanation for the predisposition of male subjects to OSA. Also, the long(L) allele was associated with a higher AHI and a longer time spent during sleep at oxygen desaturation levels below $90 \%$. On the contrary, the presence of short(S) allele seems to have a protective role in the development of sleep apnea, but it affects the quality of sleep by promoting insomnia and depression.

The rationale of the review is to obtain quality systematic data regarding early detection of patients at risk for OSA, considering that the current diagnosis algorithm detects the disease at an advanced stage and does not provide consistent preventive measures.

The objective of the study is to identify the effects of serotoninergic system on the metabolism and its implication in the pathogenesis of obesity and to assess the influence of genetic factors in OSA, which represents an important step towards identifying people at increased risk for OSA and its complications. The literature has evidenced a link between genetic factors and OSA and possibly this is why symptoms of sleep apnea have been found to run in the family. ${ }^{12,13}$ Moreover, it is stipulated that a percentage of $35-40 \%$ of OSA variance is attributed to genetic factors, which are associated with body fat distribution, craniofacial structure, and neural control of the upper airway muscles. ${ }^{14-16}$

\section{Materials and Methods}

For this review, the PRISMA statement was followed and a protocol for the review process was developed in advance. ${ }^{17}$ The main question for the review was what is the polymorphism of serotonin transporter gene involved in the development of OSA? The sub-question was what is the role of each polymorphism in the pathogenesis of OSA 
and if peripheral serotonin has a role in this syndrome by increasing the risk of obesity? The search terms were "serotonin transporter gene", "peripheral serotonin", "brain serotonin", and "OSA". The team that perform the search consisted of two authors: ADM, DAT.

\section{Protocol and Registration The Study Was Not Registered}

Studies that were included were (randomized) controlled trials and observational studies with and without control groups (cohort, case-control, cross-sectional). The inclusion criteria for this study were diagnosis of OSA, age 18 years or older, useable quantitative data concerning serotonin transporter gene or peripheral serotonin in a group of participants with OSA. For an article to be considered as potentially included in the review it had to be available in full text, written in English, and had to be published in the last 15 years (from 1st of January 2005 until 28th of May 2020). Studies that were not included were reviews and case reports.

Information sources and search were obtained from PubMed and in the Cochrane Library. The last updated search was performed on 28 May 2020. In PubMed the following search query was used: Brain Serotonin [MeSH terms] OR Serotonin Transporter Gene Polymorphism [all fields] OR Peripheral 5-HydroxyTryptamine [MeSH terms] AND Obstructive Sleep Apnea [MeSH terms] OR Sleep Disorder Breathing [all fields]. In Cochrane Library the following terms were used: brain serotonin AND OSA or serotonin transporter gene OR Peripheral 5-Hydroxytryptamine AND Sleep.

The data collection process action was performed by one author and was checked by two other authors. The following data were extracted: (1) participant characteristics, including age and OSA diagnosis (established through polysomnography, with an AHI threshold for each study as indicated in Table 1), (2) study selection by design, e.g., cross-sectional, case-control, cohort study or (randomized) controlled trial and (3) baseline measures, including the detection of any polymorphism in serotonin transporter gene and the serum titer of peripheral serotonin.

\section{Data Items}

The list of the variables for which data were sought is found in Table 2.

\section{Summary Measures and Synthesis of Results}

The principal summary measures and the methods of handling data and combining results of studies are not applied.

The titles, abstracts, and full texts were screened independently by two reviewers (ADM, DAT) according to the pre-established protocol and the inclusion and exclusion criteria mentioned above; they were verified by other two authors. (IRB, AC). Disagreements between reviewers (ADM, DAT) were resolved by consensus.

The risk of bias within studies was critically appraised by two reviewers (ADM, DAT). For cross-sectional, casecontrol, and cohort studies, the Newcastle-Ottawa scale (NOS) was used and for (randomized) controlled trials the Delphi list. The diagnosis of OSA was considered adequate if it used the American Academy of Sleep Medicine (AASM) criteria (polysomnography in Sleep Laboratory or at home with portable devices, with an AHI threshold for each study as indicated in Table 1). ${ }^{4,18,19}$

\section{Results}

After the first search, we found a total of 1210 articles. Of these, 406 studies were excluded because of duplication. The full texts of 804 studies were assessed in more detail, and 658 were subsequently excluded based on title and abstract study, because of lack of relevant information. Subsequently, a total of 146 articles were assessed for eligibility and 103 were excluded. A total of 43 studies were selected [17] and met the inclusion criteria, so they were processed for critical appraisal and data extraction. [15]. The flow chart of the search is presented in Figure 1.

The articles included in this study were classified by their topic. Therefore, the analysis included serotonin and its metabolic effects -10 articles, genetic effects -4 articles and serotonin and obesity -8 articles. The rest of the material, 21 articles dealt with general data regarding the serotoninergic system and its indirect mechanisms and actions that may be connected with the development or aggravating OSA.

Serotoninergic system showed multiple metabolic effects that are summarized in Table 3.

Serotonin defects and obesity are highly correlated as shown in multiple studies from the literature. The association is of great importance due to the fact that OSA and obesity are strongly related and share a bidirectional 


\begin{tabular}{|c|c|c|c|c|c|c|c|c|}
\hline 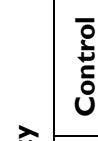 & $- \pm \stackrel{\stackrel{n}{m}}{-}$ & 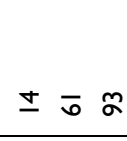 & $m$ F ন & - 으 & $\stackrel{\infty}{\wedge} \dot{\sim} \stackrel{\infty}{\infty}$ & $O \approx \stackrel{n}{n}$ & $\stackrel{m}{m} \cong \overline{\underline{m}}$ & 台 \\
\hline 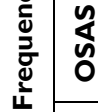 & $m$ ㄱ $\bar{\infty}$ & $m \stackrel{m}{a}$ & ๑ ా ర్సి & $\infty \stackrel{\sim}{\sim}$ & in $m$ i & $\bullet \stackrel{\circ}{\sigma}$ & 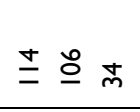 & ㅇำ \\
\hline 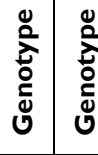 & 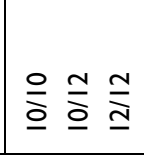 & 읗 흘 & 으흠 & 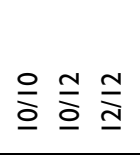 & $\tilde{n}$ & $\tilde{\omega}$ & 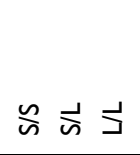 & 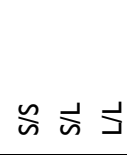 \\
\hline 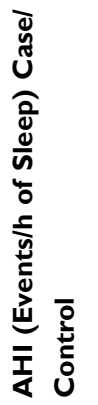 & $\bar{\Sigma} 气$ & $\bar{z} \tilde{z}$ & 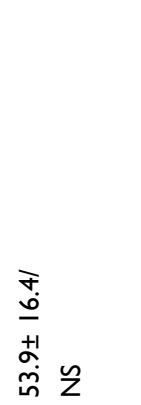 & 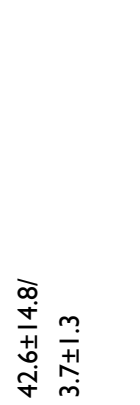 & जे 气 & $\bar{z} \tilde{z}$ & 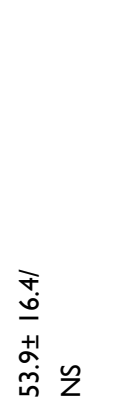 & 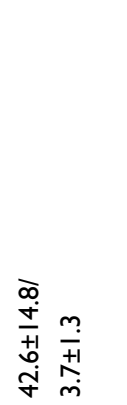 \\
\hline 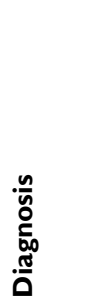 & 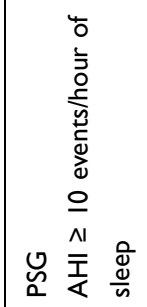 & પূ & 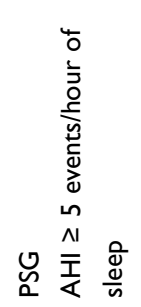 & 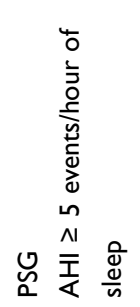 & 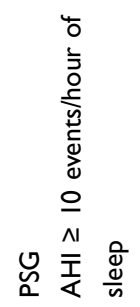 & 包 & 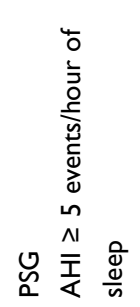 & 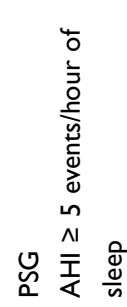 \\
\hline 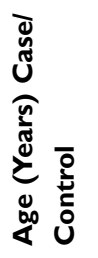 & 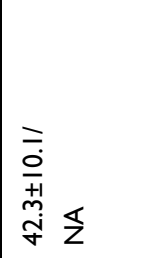 & z & 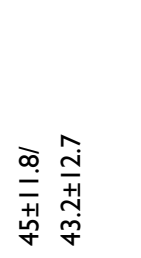 & 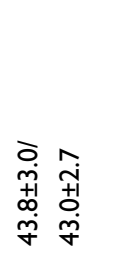 & 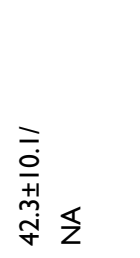 & z $\frac{1}{z}$ & 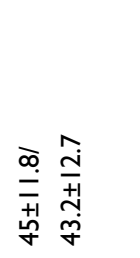 & 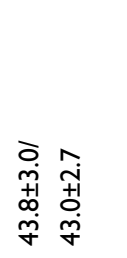 \\
\hline 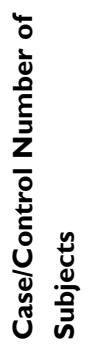 & 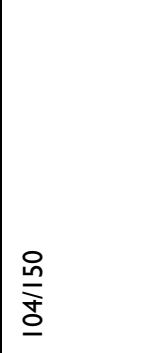 & 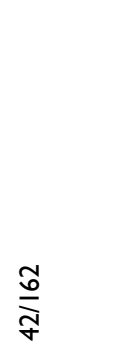 & $\begin{array}{l}\stackrel{\infty}{N} \\
\stackrel{\sim}{+} \\
\stackrel{\sim}{N}\end{array}$ & $\stackrel{\stackrel{n}{O}}{\equiv}$ & $\frac{\text { 유 }}{\text { 豆 }}$ & $\frac{2}{\frac{2}{6}}$ & 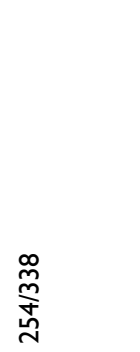 & 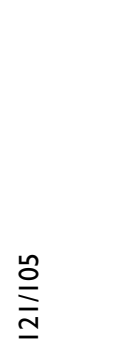 \\
\hline 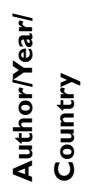 & 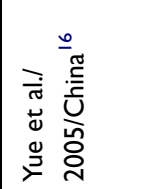 & 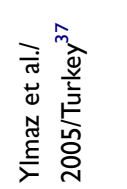 & 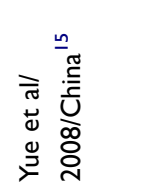 & 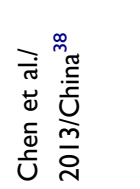 & 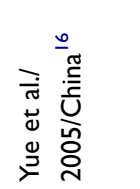 & 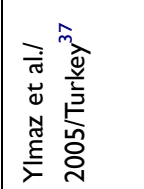 & 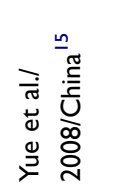 & 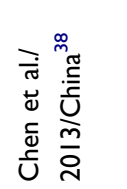 \\
\hline & \multicolumn{4}{|l|}{ 贞秽 } & \multicolumn{4}{|l|}{ 点 } \\
\hline
\end{tabular}


Table 2 Variables for Which Data Were Sought

Serotonin receptor implicated (HTRIA, HTRIB, HTRIF, HTR2A, HTR2B, HTR2C, HTR3, HTR3B, HTR7)

Gene implicated (, TPHI, SLCI8AI, SLC6AI4)

Genotype (SS, SL, LL, 10/10, 10/12, 12/12)

Serotonin gene polymorphisms (5 HTT VNTR, 5 HTT LPR)

Age (years)

AHI (events/hour of sleep)

BMI $\left(\mathrm{kg} / \mathrm{m}^{2}\right)$

Waist circumference $(\mathrm{cm})$

relationship. The results are summarized in Table 4. Correlation between genetic features and serotoninergic system is presented in Table 1 .

From the 43 articles approaching the subject, 25 were case-control trials, as expected for a less studied association like the one between serotonin and OSA. Still, this may be due to a review limitation and further research is needed.

The current analysis consists of heterogenic material represented by uneven samples, combination between animal models and experimental human tests, and different evaluation tests used that may be a source of bias within and across the studies.
Although the 43 articles included in the systemic analysis respected the general inclusion criteria, the present study may have its limitations due to multiple discrepancies in terms of follow-up period for each experiment, different kinds of experimental procedures, different subjects included, that taken together may modify the accuracy of the results. Moreover, one cannot underestimate the difference existing between in vitro, animal models and in vivo phenomena, or the potential differences in human brain versus rodent models.

\section{Discussion}

\section{Risk Factors}

Due to the endemic obesity worldwide, the prevalence of OSA is twice as high in obese subjects compared to normal-weight adults. Central obesity has become the major risk factor for its development, especially because it affects the physiological mechanism of the upper airway and modifies its shape, promoting collapsibility. In addition, specific symptoms of OSA, especially excessive daytime sleepiness may accelerate weight gain due to reduced physical activity and energy expenditure. $5,39,40$

In the adult population, another important symptom of OSA, fragmented sleep as well as sleep deprivation or
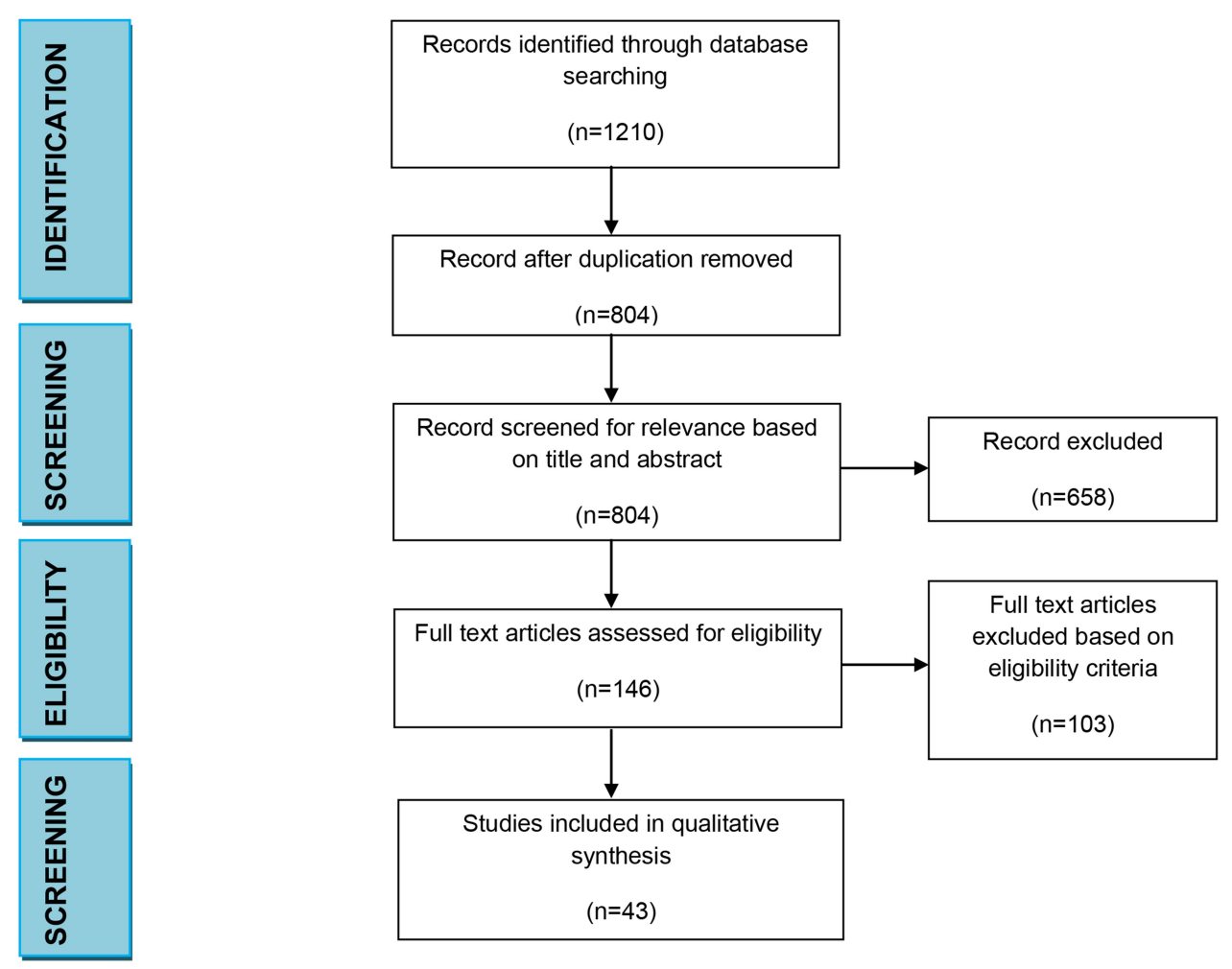

Figure I Search results. 
Table 3 Peripheral Effects of Serotonin

\begin{tabular}{|c|c|c|c|}
\hline Peripheral 5-HT & Author, Year & $\begin{array}{l}\text { Receptor } \\
\text { Implicated }\end{array}$ & Findings \\
\hline \multirow[t]{3}{*}{ In the liver } & Ramnanan et al, $2010^{20}$ & HTR2B & $\begin{array}{l}\uparrow \text { liver gluconeogenesis } \\
\downarrow \text { glucose uptake in the fasted state }\end{array}$ \\
\hline & Watanabe et al, $2010^{21}$ & HTR 2B & $\begin{array}{l}\text { Regulate hepatic bile acid turnover and lipid } \\
\text { metabolism }\end{array}$ \\
\hline & Crane et al, $2015^{22}$ & HTR2B & $\uparrow$ steatosis \\
\hline \multirow[t]{5}{*}{ In the pancreas } & $\begin{array}{l}\text { Ohta et al, } 2011^{23} \\
\text { Almaca et al, } 2016^{24} \\
\text { Bennet et al, } 2016^{25}\end{array}$ & HTR3 & Acts as a local autocrine/paracrine signal \\
\hline & Paulmann et al, $2009^{26}$ & HTR3 & $\begin{array}{l}\text { Is required for normal insulin secretion } \\
\uparrow \text { insulin exocytosis }\end{array}$ \\
\hline & Bennet et al, $2016^{27}$ & HTR 2B & $\uparrow$ glucose - stimulated insulin secretion \\
\hline & Almaca et al, $2016^{24}$ & HTRIF & $\downarrow$ glucagon secretion \\
\hline & $\begin{array}{l}\text { Kim et al, } 2010^{46} \text { Ohara-Imaizumi et al, } \\
2013^{28}\end{array}$ & HTR2B & $\begin{array}{l}\text { Increase beta cell mass } \\
\uparrow \text { glucose-stimulated insulin secretion }\end{array}$ \\
\hline \multirow[t]{3}{*}{$\begin{array}{l}\text { In the adipose } \\
\text { tissue }\end{array}$} & Ramnanan et al, $2010^{20}$ & NS & $\begin{array}{l}\uparrow \text { circulating non-esterified fatty acids (NEFA) } \\
\uparrow \text { glycerol levels }\end{array}$ \\
\hline & $\begin{array}{l}\text { Crane et al, } 2015^{22} \\
\text { Oh et al, } 2015^{8}\end{array}$ & HTR3 & $\downarrow$ adipose tissue thermogenesis \\
\hline & Oh et al,2015 & $\begin{array}{l}\text { HTR2B } \\
\text { HTR2A } \\
\text { HTR3 }\end{array}$ & $\begin{array}{l}\uparrow \text { adipose tissue lipolysis during fasting } \\
\uparrow \text { lipogenesis in adipose tissue in response to high fat } \\
\text { diet } \\
\downarrow \text { adaptive thermogenesis. }\end{array}$ \\
\hline
\end{tabular}

Table 4 Serotonin and Obesity

\begin{tabular}{|c|c|c|c|c|}
\hline Author, Year & Region & Sample & Gene/Receptor Implicated & Association \\
\hline Haahr, 2015 29 & Denmark & 21 & HTR2A & BMI, weight gain \\
\hline Fukui, $2012^{30}$ & Japan & 311 & NS & Insulin resistance syndrome \\
\hline $\mathrm{Li}, 2014^{31}$ & Europe and US & 1982 & HTR2A & $\mathrm{BMI}$ \\
\hline Opgen, $2010^{32}$ & Germany & 128 & HTR2C & Weight gain \\
\hline Chen, $2013^{33}$ & China & 478 & $\begin{array}{l}\text { SLCI8AI } \\
\text { HTR3B } \\
\text { HTR2A } \\
\text { HTR2C }\end{array}$ & BMI \\
\hline Kwak, $2012^{34}$ & Korea & 8842 & TPHI & BMI and waist circumference \\
\hline Halder, $2007^{35}$ & Europe & 934 & HTR2A & Central obesity, metabolic syndrome \\
\hline Corpeleijn, $2010^{36}$ & Europe & 722 & SLC6AI4 & BMI, fat, oxidation in women \\
\hline
\end{tabular}

Abbreviation: NS, not specified. 

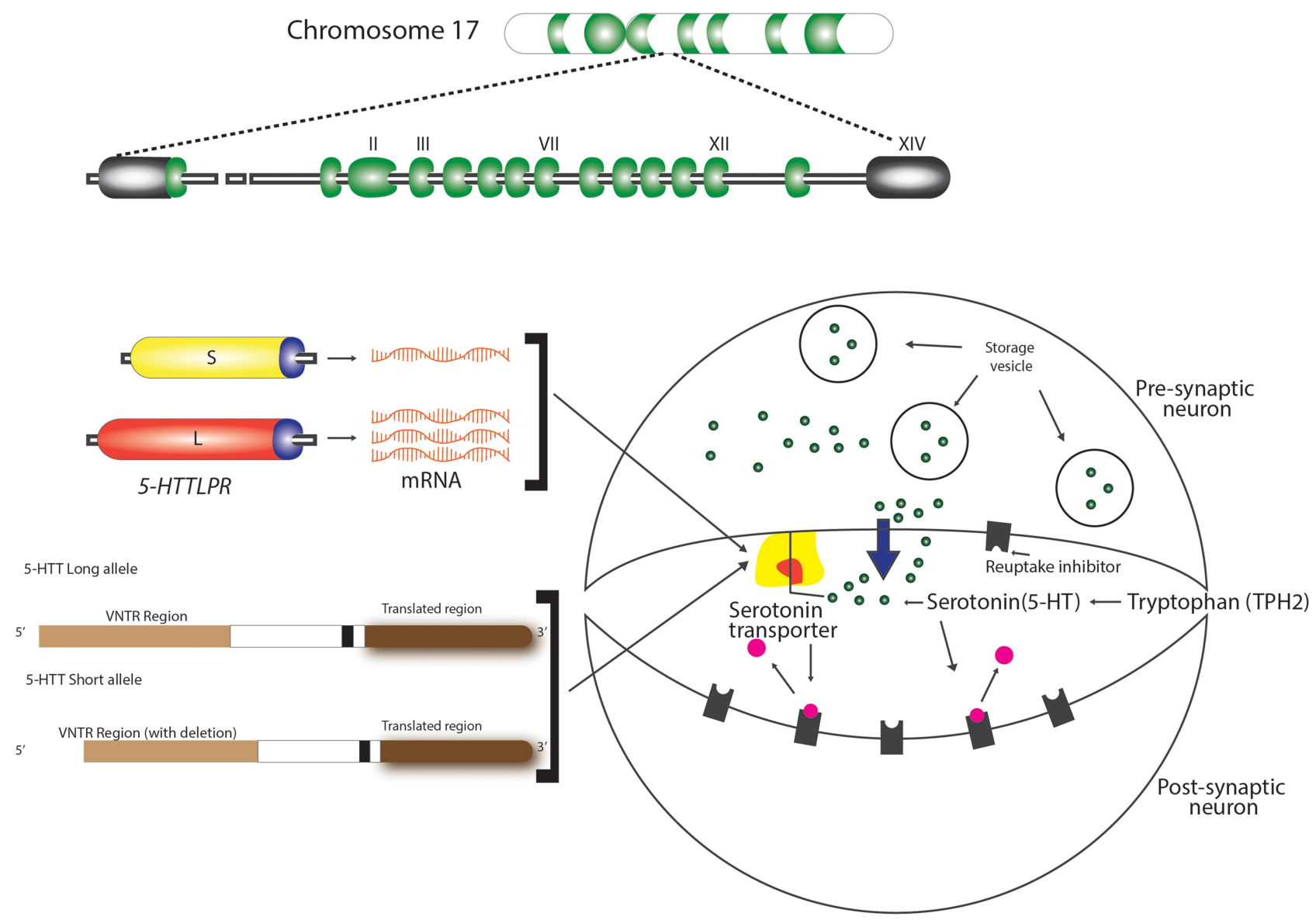

Figure 2 Intrasynaptic transport of serotonin. Polymorphisms of serotonin transporter gene (STG) - 5-HTTLPR and 5-HTTVNTR.

self-reported short sleep ( $<6$ hours/night), have been associated with metabolic disturbances independent of obesity and OSA, suggesting important interactions between these conditions and increased complexity of their treatment. ${ }^{41-43}$

Furthermore, a weight gain of $10 \%$ of body baseline in subjects diagnosed with mild OSA is associated with a sixfold higher risk of OSA aggravation. Also, a weight loss of $10 \%$ of baseline reduces the severity of OSA by $20 \%{ }^{44}$

The development of obesity is multifactorial. There are two pathways that control feeding behavior, namely the homeostatic and hedonic systems. The homeostatic system is primarily located in the hypothalamus and brainstem and is responsible for the integration of energy availability from different organs and brain regions and for adjusting the food intake to balance energy reserve and expenditure. ${ }^{11,45}$ The center of the hedonic system is considered to be the striatum, one of the nuclei in the subcortical basal ganglia. Its role is to control the motivational and rewarding aspects of food intake and is closely connected to the homeostatic system. ${ }^{45,46}$

Two independent serotonin systems exist, one in the brain and the other in the periphery. As evidenced in literature, serotonin acts as a modulatory neurotransmitter and is a biogenic amine synthesized in the central nervous and in the enteric nervous system. Brain serotonin is synthesized from the amino acid precursor tryptophan 2, packaged into vesicles, and released into the synapse following an action potential. Once in the synapse, serotonin can interact with both the pre- and postsynaptic receptors. However, immediately after reacting with the pre- and postsynaptic receptors, it is critically important that serotonin be removed from the synapse (Figure 2). Brain serotonin is responsible for the regulation of mood, cognitive and autonomic functions in order to ensure survival, reproduction and to maintain homeostasis. In addition, serotonin has an excitatory effect on the respiratory function causing the excitation of phrenic motor neurons, 
diaphragmatic contraction, and dilatation of upper airway muscles. ${ }^{47}$

On the other hand, close to $98 \%$ of the body's serotonin exists peripherally, where it operates as a peripheral hormone, affecting vasoconstriction, intestinal motility, primary hemostasis, liver repair, and the control of the T-cell-mediated immune system. ${ }^{48,49}$

The main neurotransmitters of hedonic and homeostatic systems are dopamine and serotonin, but other neurotransmitters are also involved. ${ }^{50}$ There are two hypothesis that can explain caloric consumption: first, the reward deficiency hypothesis implying that people increase the food intake due to a decrease in the dopaminergic activity and second, the homeostatic hypothesis that implies a higher consumption of food due to disturbed homeostatic balance through a decreased level of serotonin in the hypothalamus. ${ }^{7}$

The influence of serotonin on obesity is not yet very clear, mainly because the relationship between intrasynaptic serotonin level and the binding potential (BP) of the transporter of brain serotonin (SERT) is not clarified. Despite the fact that morbid obesity patients (Body mass index - BMI $>40 \mathrm{~kg} / \mathrm{m} 2$ ) did not differ in SERT BP, in overweight/moderate obesity subjects the level of SERT BP is elevated compared to lean controls. ${ }^{29,51}$ Thus, it was stipulated, that serotonin levels and brain serotonin transporter binding potential (SERT BP) have an inversed relationship due to other factors than body weight, such as insulin resistance. It cannot be ruled that this relationship is not bidirectional because most of the time obesity is associated with moderate-to-severe insulin resistance. In addition, decreased SERT is seen in $30 \%$ of patients with binge eating and additional variation may occur due to diet composition and meal timing. ${ }^{7}$

Even if there is an amount of free serotonin in plasma, the main organ responsible for the secretion of peripheral serotonin is the gut, which produces it in the enterochromaffin cells (ECs). Indigenous bacteria produce metabolites that signal the colonic enterochromaffin cells. ECs increase tryptophan 1 (Tph1) expression and the biosynthesis of serotonin. 5-HT is secreted basolaterally and luminally, thus stimulating of myenteric neurons, gut motility, and gut inflammation. In addition, as shown in Figure 3, peripheral serotonin has many effects on other organs and has been studied extensively, as synthesized in Table 3. In the liver, it increases steatosis, gluconeogenesis and inhibits glucose uptake in the fasting state. In the pancreas, 5-HT increases the insulin production and influence $\beta$-cell proliferation. Also, the 5-HT influences the development of the obesity, by influencing the lipolysis and increasing the lipogenesis in the white adipose tissue. Beside this, in the brown adipose tissue, serotonin is influencing the thermogenesis. The levels of peripheral serotonin are associated with obesity as shown in several studies which have demonstrated increased blood serotonin levels in animals with obesity and diabetes. ${ }^{8}$ In addition, Kim et al concluded that mice with high fat diet have had higher serum levels of serotonin compared to lean mice. ${ }^{52}$ The main metabolite of serotonin is 5-hydroxyindoleacetic acid (5-IAA) and its levels have been higher in the plasma and urine of obese subjects, positively correlated with fasting blood glucose and hemoglobinAlc (HbAlc). ${ }^{30,53}$ Similarly, greater tryptophan 1 expression and elevated plasma serotonin concentration were observed in rats with high-fat diet. ${ }^{54}$ There is a bidirectional relationship between serotonin and OSA because obesity influences the circadian rhythm and the meal-induced release of serotonin in the duodenum; therefore, these data confirm that increased levels of serotonin are positively associated with obesity and type 2 diabetes. ${ }^{55}$

It is a well-known fact that the prevalence of OSA increases with age and is 2 to 3 times higher in men compared to women. Besides, there is the craniofacial phenotype that predispose to OSA consisting in hyoid position, tonsillar hypertrophy, mandibular size, and decreased velopharyngeal area. Another factor responsible for OSA is smoking, with controversial data, causing lipid and glucose metabolic dysfunction, endothelial injury, and systemic inflammation. ${ }^{4,56,57}$

\section{Genetic Implication}

An important component of OSA is the central nervous system control of the upper airway muscles, including genioglossus, which is innervated by neurons from the hypoglossal nucleus and is recognized as the main extrinsic tongue protuzor muscle (the patency of the airways and the regular pattern of breathing during sleep is maintained though the contraction of this muscle). The serotonergic and noradrenergic cells are capable to regulate the airway function and have become an indispensable component of the regulatory system for brain control of breathing because these are responsible for an increased activity of the genioglossus muscle. ${ }^{2,58,59}$

In addition, there are some polymorphisms in the genes for serotonin receptors responsible for metabolic diseases 


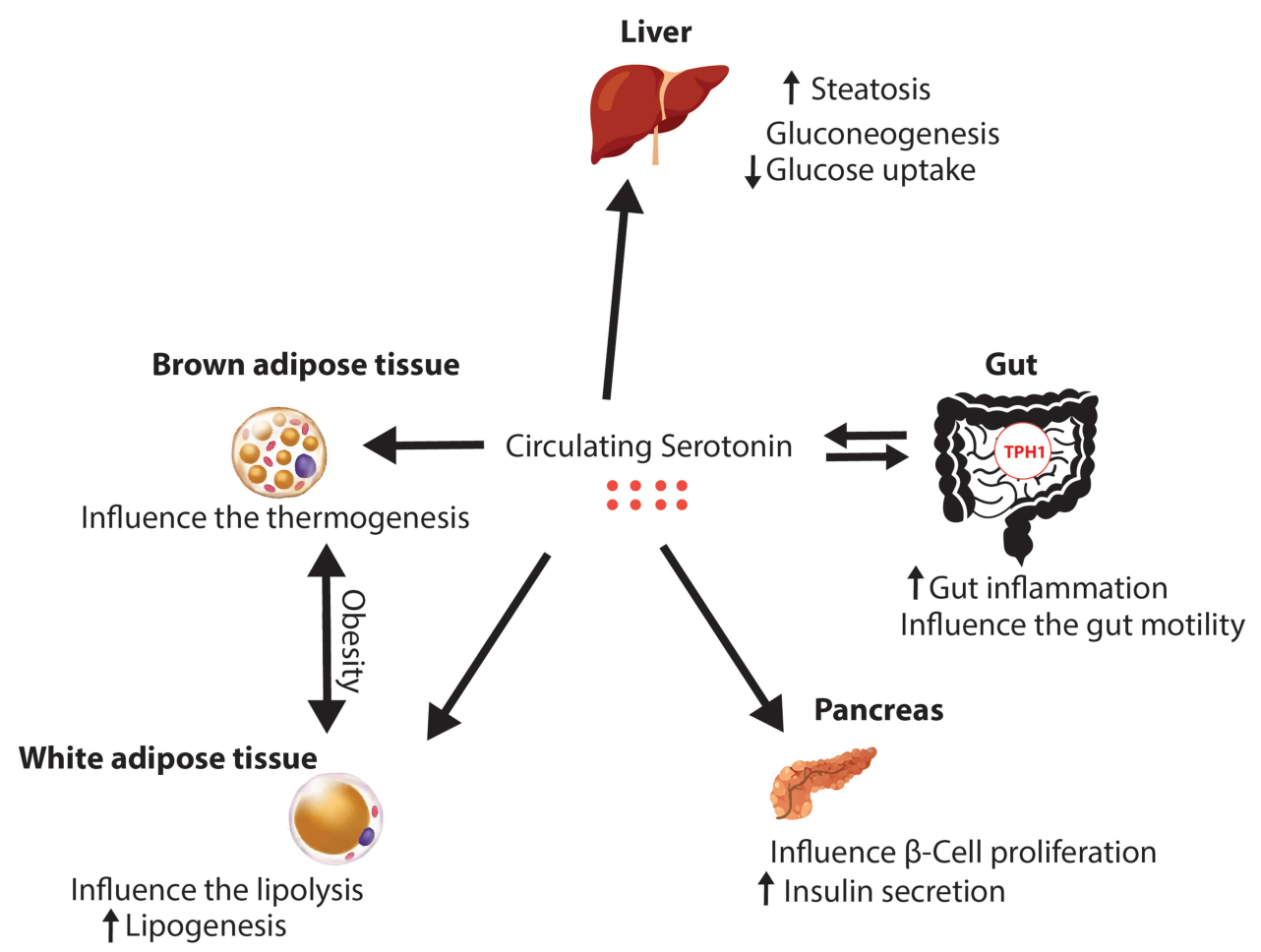

Figure 3 Peripheral effects of serotonin.

and obesity. Some studies demonstrated that particularly the receptors of serotonin(HTR) 2A variants are associated with higher waist circumference, higher body max index, and metabolic syndrome. ${ }^{31,60,61}$ Also, the polymorphisms of the HTR2C gene determined in some patients weight gain and an increased BMI. ${ }^{55,56}$ Thus, there is genetic evidence that supports a positive correlation between the variable expression of genes that control serotonin synthesis, as demonstrated by Kwak et al, who showed that a variant of the tryptophan 1 gene was associated with an increased BMI and waist circumference. ${ }^{34}$

Overall, serotonin is responsible for an energy storage phenotype under fed conditions, consisting of suppressed lipolysis, enhanced adipogenesis in white adipocytes (through HTR2A signaling), and lipid uptake. ${ }^{47}$

\section{Serotonin and Sleep Architecture}

Due to the multiple connections of serotonergic neurons with the cortex, the limbic system, the basal forebrain, and the brainstem areas, serotonin has an important influence on sleep/wake cycles consisting in the inhibition of rapideye movement (REM) sleep and promoting wakefulness. The effects of serotonin receptors depend on the specific $\mathrm{BP}$, for example, the agonists of HTR1A are responsible for increasing REM sleep, while local administration of
HTR2A/2C, HTR1B, HTR7, and HTR3 agonists decreases the duration of REM sleep in mouse models, without changing the slow wave sleep pattern. In patients with primary insomnia or normal sleep, the systemic administration of HTR2A antagonists reduces wakefulness and can increase the duration of slow wave sleep. ${ }^{62,63}$ Buchanan et al showed that mice with selective loss of serotonin neurons exhibit loss of response to hypercapnia. ${ }^{64}$ As shown in another study, the arousal mediated by the 5-HT system has a role in protecting patients against severe hypercapnia by decreasing the length of apneic episodes, taking into account that in mice the administration of antagonist of the HTR2A has a dose-dependent effect on the reduction of hypercapnia during arousals. ${ }^{64,65}$

\section{Serotonin and Sleep-Disordered Breathing}

During sleep, there is a diminished serotonin ventilatory stimulation, which can contribute to upper airway collapse. ${ }^{66,67}$ In addition, multiple studies showed, through functional neuroimaging techniques, an important decrease of the 5-HT receptors responsible for an increased prevalence of OSA in older subjects, which reaches $62 \%{ }^{68}$ This fact is augmented by 
the influence of the serotonergic system on depression, which is highly associated with OSA despite controlling for obesity or hypertension. ${ }^{69-71}$ In Prader-Willy Syndrome (PWS) patients, there is a reduction in brain serotonin activity and it was stipulated that in these subjects OSA manifests prior to obesity, suggesting a vital role of central serotonin in its development. Serotonin reduces food intake and thus appropriate agonists for its receptors are possible valuable drugs. Among these, sibutramine, as an unspecific inhibitor of serotonin and norepinephrine reuptake, was proposed in PWS patients, after considering favorable results obtained in obese patients and in hypothalamic obesity. ${ }^{72}$

Veasey et al demonstrated that the English bulldog, given its upper airway anatomy, is predisposed to OSA, so when serotonin antagonists were administrated, the desaturations were more important and snoring was observed even during wakefulness due to a reduced airway dilator muscle activity. ${ }^{67}$ In addition, there is an inverse relationship between brain serotonin levels and food intake. Therefore, 5-HT was considered an anorexigenic neurotransmitter and has become a target for anti-obesity treatment. ${ }^{73}$

\section{Serotonin Transporter Gene}

Another area of research used in sleep disorder breathing is the study of serotonin transporter gene (5-HTT) polymorphism, responsible for the interactions between serotonin and its receptors, in order to control the reuptake of serotonin and the peripheral actions of $5-\mathrm{HT}^{38}$

The encoding 5-HTT gene is located in the 17q11.117 q12 region of Chromosome 17, as shown in Figure 1. ${ }^{74}$ Previous studies have identified two polymorphisms of this gene (5-HTTLPR and 5-HTTVNTR), also illustrated in Figure 1, that influence the intrasynaptic serotonin concentration and are implicated in sleep disorder, psychological diseases, and other associated OSA phenotypes, as seen in Table 1. These consist of a 44-base pair (bp) insertion/deletion in the located at the 5', flanking regulatory region resulting in short $(\mathrm{S})$ and long $(\mathrm{L})$ alleles (5-HTTLPR). The "L" allele is associated with normal levels of serotonin transporter, whereas the " $\mathrm{S}$ " allele is associated with reduced serotonin transporter expression and a non-coding variable tandem repeats of 9, 10 and 12 in the second intron of 5-HTT gene (STin2.VNTR) that alters the 5-HTT gene transcription, enhance the normal function and therefore modify serotonin reuptake. As explained before, the functions of the upper airway dilator muscles are influenced by serotonergic neurons, which are governed by the 5-HTT gene, so this can be involved in the susceptibility of OSA. ${ }^{15}$

In 2005, Yue et al studied on a group of 104 patients and 150 healthy controls the frequencies of different forms of the genotypes and alleles of the 5-HTT gene. The average age of the study group was $42.3 \pm 10.1$ years and they were diagnosed with OSA by polysomnography (AHI $\geq 10$ events/h of sleep). The frequency of $\mathrm{S} / \mathrm{S}, \mathrm{S} / \mathrm{L}$, or $\mathrm{L} / \mathrm{L}$ genotypes and of the $\mathrm{S}$ and $\mathrm{L}$ alleles was not significantly different between the study and the control group. They observed that in 5-HTTVNTR polymorphism, the frequencies of 10/10 and 12/10 genotypes were higher in the OSA group. The study concluded that the allele 10 of 5-HTTVNTR polymorphism can be considered a susceptible factor in the development of OSA, moreover because in this study the allele 10 was significantly higher in the OSA group compared to the healthy subjects. ${ }^{16}$

Ylmaz et al included in their study 42 subjects diagnosed with OSA by polysomnography and 162 healthy controls and found that the 12/12 5-HTTVNTR polymorphism was recognized in $54.3 \%$ of the patients from the control group and $36 \%$ of the patients from the case group, while the $12 / 10$ polymorphism was diagnosed in $37 \%$ in the control group and $52 \%$ in the case group and the $10 / 10$ polymorphism was observed in $8 \%$ of the control group and $12 \%$ of the case lot. For 5-HTTLPR polymorphism L/L, L/S, S/S variants were $21.3 \%, 44.4 \%, 33.8 \%$ in control subjects and $14.8 \%, 59.3 \%$, $29.3 \%$ in the OSA group. Regarding these two polymorphisms, there was no difference between the genotypes and allele frequencies of the OSA group and controls or between male and female control subjects. However, in female subjects, it seems that $12 / 12$ and $\mathrm{S} / \mathrm{S}$ genotypes were more frequent, while in male patients the most represented genotypes were $12 / 10$ and $\mathrm{L} / \mathrm{L}$. Thus, a higher frequency was determined in male patients, compared to controls, but the genotypes of female patients and controls were not significantly different. The clinical data of the patients with different genotypes were compared according to gender and no statistically significant difference has been found. ${ }^{74}$

Yue et al developed a study in 2008 comparing 254 OSA subjects diagnosed by polysomnography (AHI $>5$ events/h of sleep) with 338 control participants. The average age in the study group was $45 \pm 11.8$ years and in the control group it was $43.2 \pm 12.7$ years. The mean apnea/hypopnea index in the study group was $53.9 \pm 16.4$ events/hour of sleep. This study took into consideration the two polymorphisms of the 5-HTT gene and demonstrated that the allele 10-repeat of the 5-HTTVNTR polymorphism was associated with OSA, both 
in total and male subjects. Even if 5-HTTLPR is not known to predispose to OSA, the presence of L allele was significantly different in male patients than in male controls. Haplotype analysis was more significant than single-locus analysis. Their study showed that there are two haplotypes (S-12 and L-10) highly associated with OSA in a subgroup of male patients $(\mathrm{p}=0.0006)$. This is an evidence which can explain the implication of the 5-HTT gene in the pathogenesis of OSA and also the reason why in male subjects the prevalence of OSA is higher than in female subjects (2-4:1). In addition, this study shows that the presence of the STin2.10 allele of the 5-HTT gene may influence the development of OSA in $21.3 \%$ of the patients. There are some mechanisms that can explain this association. First of all, the repetitive sequence of this polymorphism is followed by a binding site for a transcription factor, which is an activating protein (AP-1) with an important role in 5-HTT expression. Secondly, the stability of the gene transcription through messenger ribonucleic acid (RNA) is influenced by the number of VNTR repeats. Similarly, 5-HTTVNTR interacts with insulin gene locus insulin-dependent diabetes mellitus 2 (IDDM2) and this can interfere with the expression of insulin messenger ribonucleic acid (RNA) in pancreatic cells. ${ }^{15}$

Chen et al included in their study 121 patients diagnosed with OSA by polysomnography (AHI $\geq 5$ events/h of sleep) with an average of $43.8 \pm 3.0$ years and an AHI of $42.6 \pm 14.8$ events/h of sleep and 105 healthy subjects with an average age of $43.0 \pm 2.7$ years and a mean AHI of $3.7 \pm 1.3$ events/hour of sleep. In this study, there were no differences in the genotype frequencies or allele distribution of 5-HTTLPR polymorphism between OSA subjects and control group. However, there were some differences regarding 5-HTTVNTR polymorphism. The frequencies of 10/10,10/12 genotypes and 10 allele were higher in OSA group versus control and also there were significant differences in genotype and allele frequencies between male OSA patients and male controls. This evidence suggests that there is a positive association between OSA and 5-HTT polymorphism and that the allele 10 of 5-HTTVNTR might become a susceptible factor in the development of sleep disorders. ${ }^{38}$ Kunugi et al conducted a study that took into account the serotonin transporter gene polymorphism in patients with bipolar affective disorders and found that there are significant ethnic differences between the Chinese Han and European American population in terms of genotype or allele frequencies of 5-HTTLPR and STin2.VNTR in the 5-HTT gene. ${ }^{75}$ Similar to the study of Yue et al, which stipulated that the allele 10 repeat of STin2.VNTR was associated with OSA in both total and male subjects and that the $\mathrm{L}$ allele showed significant differences between OSA male and male controls, the study of Chen et al revealed same results. Therefore, they concluded that the 5-HTT gene polymorphism is highly associated with OSA and the allele 10 of the 5-HTTVNTR polymorphism might be a susceptible factor for OSA. ${ }^{15,38}$

Regarding the genotypes and allele frequencies, in the study of YImaz et al, there were no significant differences between OSA patients and controls or between the two sexes in the control group. ${ }^{37}$ However, a genetic predisposition to OSA in male patients was suggested, based on significant differences between OSA male and male controls, which lead to an alteration in the activity of the serotonergic system. Therefore, there is a six-fold increase in the risk of OSA in men subjects compared with women subjects, based on sleep laboratory data and genetic differences. Despite these, there are no significant differences between the clinical data regarding different genotypes, which suggests that other mechanisms are involved in the development of OSA. In addition, the frequency of the $\mathrm{S}$ allele and $\mathrm{S} / \mathrm{S}$ genotype was less frequent in male patients resulting in a decreased 5-HT reuptake. This may lead to a shorter serotonergic activity in these subjects which can explain the diagnosis of OSA. ${ }^{76}$ Contrarily, Sookoian et al conducted a study on rotated shift workers and proved that they have S allele 5-HTTLPR polymorphism and a decreased level of serotonin and thus both these modifications can explain why these subjects can adapt to the conditions imposed by rotating shift work. ${ }^{77}$

On the other side, in male patients, the $\mathrm{L} / \mathrm{L}$ genotype was more frequent resulting in faster reuptake of serotonin and shorter serotonin activity. Thus, this modificationpredisposes male subjects to develop OSA. Also, in older Caucasian, the $\mathrm{L}$ allele was associated with a higher $\mathrm{AHI}$ and a longer time spent during sleep at oxygen desaturation levels below $90 \%$, as Schroder et al have demonstrated. ${ }^{78}$ The L/S genotype is associated with moderate serotonin reuptake activity and is also more frequent in male patients, which can also explain the high prevalence of OSA in male patients, especially in those with an absent $\mathrm{L} / \mathrm{L}$ genotype. There is an indirect proof that the presence of $\mathrm{S}$ allele is a protective factor against OSA. The allele 12 of 5-HTTVNTR polymorphism and the 12/12 genotype was more frequent in female patients compared to male patients. Meanwhile, the 12/12 genotype was more frequent in male controls and the 12/10 genotype was overrepresented in male patients. ${ }^{78}$

Contrarily, the study of Yue et al suggested that allele L of 5-HTTLPR and allele 10 of 5-HTTVNTR are susceptible factors for OSA in male patients. ${ }^{15}$ Also, Chen et al support 
that the allele 10 of 5-HTTVNTR might be a susceptible factor in the pathogenesis of OSA. ${ }^{38}$

Schroder et al conducted a study on 94 subjects diagnosed with OSA using home polysomnography and observed that the patients with L/L genotype of 5-HTTLPR phenotype were older, with an average age of 73.25 years and had a higher AHI of $16.11 \pm 16.3$ events $/ \mathrm{h}$ of sleep and more important desaturations during sleep. ${ }^{78}$

As discussed before, serotonin pathway affects anxiety, food intake, sleep, sexual behavior, and mood. ${ }^{79}$ Even if $2 \%$ of the total serotonin is stored in the central nervous system, the rest of the body's serotonin is produced by the gut and stored peripherally, where it has many effects on primary homeostasis, vasoconstriction, liver repair, and immunity. Carleij et al proved that both peripheral and central serotonin are involved in sleep regulation. The desaturations and the arousals common to OSA have a negative impact on serotonin pathway mediators. ${ }^{80}$ Tripathi et al conducted a study on 381 elderly patients and showed that in this group the level of serum serotonin was inversely correlated to OSA severity; therefore, the estimation of serum serotonin is a viable biomarker for diagnosing OSA. ${ }^{81}$

Serotonin also influences other aspects of sleep and therefore, as shown in the article of Brummet et al, the 5-HTTLPR $\mathrm{S}$ allele was associated with worsened insomnia in patients suffering from depression, poor sleep quality, and chronic stress. ${ }^{82}$ Even if, as Yue et al showed, the L allele of 5-HTTLPR was associated with OSA in male patients but not in female patients, Deuschle approved that the $\mathrm{S}$ allele of 5-HTTLPR was associated with primary insomnia in female subjects. In addition, this polymorphism is independently associated with insomnia and depression, social phobia and processing style for negative information and also there is an association between the serotonin transporter length polymorphism and primary insomnia. ${ }^{15,83}$

The limitations of this systematic review were the heterogeneity of included studies, the time limit set to the last 15 years, the bias of search, and the lack of published articles regarding this topic in the literature.

\section{Conclusions}

Numerous data from the literature have recently showed that the pathophysiology of OSA is complex and influenced by a number of factors. The genetic predisposition and the influence of neuromodulators like serotonin bring a novel approach of the pathology and open a multitude of diagnostic and therapeutic options.
The implication of serotoninergic system in the development of OSA has direct and indirect mechanisms. The correlations between serotonin and obesity, high BMI, increased abdominal circumference represent an indirect mechanism for OSA. Furthermore, serotonin is involved in numerous metabolic processes such as the increase of liver gluconeogenesis, steatosis, high levels of glucose in the blood, low levels of glucagon or lipogenesis, being a promoter of metabolic syndrome, which is also related to OSA.

The direct implication of serotonin in the development of OSA is demonstrated by genetic mechanisms. The serotonin transporter gene has two polymorphisms involved in OSA: 5-HTTVNTR and 5-HTTLPR. The allele 10 of 5-HTTVNTR might become a susceptible factor in the development of sleep disorders. Furthermore, the L/L genotype was more frequent in males, resulting in faster reuptake of serotonin and shorter serotonin activity, which leads to an explanation of a predisposition of male subjects to OSA. Also, the L allele was associated with a higher AHI and a longer time spent during sleep at oxygen desaturation levels below $90 \%$. On the other hand, the presence of $\mathrm{S}$ allele seems to have a protective role in the development of sleep apnea, but it affects the quality of sleep by promoting insomnia and depression.

In conclusion, serotonin, a molecule long-known to be involved in many physiological processes, is mainly important in sleep behavior, with a marked influence on sleep/wake cycles consisting in the inhibition of REM sleep and promoting wakefulness, with an important role in OSA. This molecule and its genetical modification must be taken into account, moreover because OSA has been shown to significantly aggregate within families with nearly $40 \%$ of AHI variation due to genetic factors.

\section{Abbreviations}

5-IAA, 5-Hydroxyindoleacetic Acid; 5-HT, Serotonin/ 5-HydroxyTryptamine; 5-HTT, Serotonin transporter gene; AHI, Apnea-hypopnea index; AP-1, Activating protein - 1; BMI, Body Mass Index; BP, Binding potential; bp, base pair; ECs, Enterocromaffin cells; HbA1c, HemoglobinA1c; HTR, Serotonin receptor; IDDM2, Insulin dependent diabetes mellitus 2; L allele, long allele; LPR, linked polymorphic region; NA, Not applicable; NOS, Newcastle-Ottawa Scale; NS, Not specified; OSA, Obstructive sleep apnea; PSG, Polysomnography; PWS, Prader-Willy Sindrome; REM, Rapid eye movement; RNA, Ribonucleic acid; S allele, short allele; SERT, Transporter of brain serotonin; SERT BP, Brain serotonin transporter binding potential; STG, Serotonin 
transporter gene; Tph1, Tryptophan 1; VNTR, variable number of tandem repeats.

\section{Acknowledgments}

The publication was funded by National Research Development Projects to finance excellence (PFE)37/2018-2020 granted by the Romanian Ministry of Research and Innovation.

\section{Author Contributions}

All authors made a significant contribution to the work reported, whether that is in the conception, study design, execution, acquisition of data, analysis and interpretation, or in all these areas; took part in drafting, revising or critically reviewing the article; gave final approval of the version to be published; have agreed on the journal to which the article has been submitted; and agree to be accountable for all aspects of the work.

\section{Funding}

The research was funded by National Research Development Projects to finance excellence (PFE)37/2018-2020 granted by the Romanian Ministry of Research and Innovation.

\section{Disclosure}

The authors report no conflicts of interest in this work.

\section{References}

1. Berry RB, Budhiraja R, Gottlieb DJ, et al. Rules for scoring respiratory events in sleep: update of the 2007 AASM manual for the scoring of sleep and associated events. Deliberations of the sleep apnea definitions task force of the American academy of sleep medicine. $J$ Clin Sleep Med. 2012;8(05):597-619. doi:10.5664/jcsm.2172

2. Dempsey JA, Veasey SC, Morgan BJ, O’Donnell CP. Pathophysiology of sleep apnea. Physiol Rev. 2010;90(1):47-112. doi:10.1152/ physrev.00043.2008

3. Lin J, Suurna M. Sleep apnea and sleep-disordered breathing. Otolaryngol Clin North Am. 2018;51(4):827-833. doi:10.1016/j. otc.2018.03.009

4. Kapur VK, Auckley DH, Chowdhuri S, et al. Clinical practice guideline for diagnostic testing for adult obstructive sleep apnea: an American academy of sleep medicine clinical practice guideline. J Clin Sleep Med. 2017;13(3):479-504. doi:10.5664/jcsm.6506

5. Young T. Risk factors for obstructive sleep apnea in adults. JAMA. 2004;291(16):2013-2016. doi:10.1001/jama.291.16.2013

6. Patel SR, Frame JM, Larkin EK. Heritability of upper airway dimensions derived using acoustic pharyngometry. Eur Respir J. 2008;32 (5):1304-1308. doi:10.1183/09031936.00029808

7. Moerlein SM, Perlmutter JS, Markham J, Welch MJ. In vivo kinetics of [18F](N-methyl)benperidol: a novel PET tracer for assessment of dopaminergic D2-like receptor binding. J Cereb Blood Flow Metab. 1997;17:833-845. doi:10.1097/00004647-199708000-00002
8. Oh CM, Namkung J, Go Y, et al. Regulation of systemic energy homeostasis by serotonin in adipose tissues. Nat Commun. 2015;6:6794. doi:10.1038/ncomms7794

9. Young T, Palta M, Dempsey J, Skatrud J, Weber S, Badr S. The occurrence of sleep-disordered breathing among middle-aged adults. $N \quad$ Engl J Med. 1993;328:1230-1235. doi:10.1056/ NEJM199304293281704

10. Redline S, Tishler PV, Tosteson TD, et al. The familial aggregation of obstructive sleep apnea. Am J Respir Crit Care Med. 1995;151 (3_pt_1):682-687. doi:10.1164/ajrccm/151.3_Pt_1.682

11. He W, Lam TKT, Obici S, Rossetti L. Molecular disruption of hypothalamic nutrient sensing induces obesity. Nat Neurosci. 2006;9(2):227-233. doi:10.1038/nn1626

12. Guilleminault C, Partinen M, Hollman K, Powell N, Stoohs R. Familial aggregates in obstructive sleep apnea syndrome. Chest. 1995;107(6):1545-1551. doi:10.1378/chest.107.6.1545

13. Berry-Kravis EM, Zhou L, Rand CM, Weese-Mayer DE. Congenital central hypoventilation syndrome: PHOX2B mutations and phenotype. Am J Respir Crit Care Med. 2006;174(10):1139-1144. doi:10.1164/rccm.200602-305OC

14. Casale M, Pappacena M, Rinaldi V, Bressi F, Baptista P, Salvinelli F. Obstructive sleep apnea syndrome: from phenotype to genetic basis. Curr Genomics. 2009;10(2):119-126. doi:10.2174/ 138920209787846998

15. Yue W, Liu H, Zhang J, et al. Association study of serotonin transporter gene polymorphisms with obstructive sleep apnea syndrome in Chinese Han population. Sleep. 2008;31(11):1535-1541. doi:10.1093/sleep/31.11.1535

16. Yue W, Liu P, Hao W, et al. Association study of sleep apnea syndrome and polymorphisms in the serotonin transporter gene. Chin J Med Genet. 2005;22(5):533-536.

17. Liberati A, Altman DG, Tetzlaff J. The PRISMA statement for reporting systematic reviews and meta-analyses of studies that evaluate health care interventions: explanation and elaboration. $J$ Clin Epidemiol. 2009;62:e1-e34. doi:10.1016/j.jclinepi.2009.06.006

18. Wells GA, Shea B, O'Connell D, Petersen J, Welch V, Losos MTP. The Newcastle-Ottawa Scale (NOS) for Assessing the Quality of Nonrandomized Studies in Meta-Analyses. Ottawa: Can Underwrit, Department of Epidemiology and Community Medicine at University. Available from: http://www.ohri.ca/programs/clinical_epi demiology/oxford.htm. 2014. Accessed January 19, 2021.

19. Verhagen AP, De Vet HCW, De Bie RA, et al. The Delphi list: a criteria list for quality assessment of randomized clinical trials for conducting systematic reviews developed by Delphi consensus. J Clin Epidemiol. 1998;51:1235-1241. doi:10.1016/S0895-4356(98) 00131-0

20. Ramnanan CJ, Edgerton DS, Rivera N, et al. Molecular characterization of insulin-mediated suppression of hepatic glucose production in vivo. Diabetes. 2010;59(6):1302-1311. doi:10.2337/db09-1625

21. Watanabe H, Akasaka D, Ogasawara $\mathrm{H}$, et al. Peripheral serotonin enhances lipid metabolism by accelerating bile acid turnover. Endocrinology. 2010;151(10):4776-4786. doi:10.1210/en.2009-1349

22. Crane JD, Palanivel R, Mottillo EP, et al. Inhibiting peripheral serotonin synthesis reduces obesity and metabolic dysfunction by promoting brown adipose tissue thermogenesis. Nat Med. 2015;21 (2):166-172. doi: $10.1038 / \mathrm{nm} .3766$

23. Ohta Y, Kosaka Y, Kishimoto N, et al. Convergence of the insulin and serotonin programs in the pancreatic $\beta$-cell. Diabetes. 2011;60 (12):3208-3216. doi:10.2337/db10-1192

24. Almaca J, Molina J, Menegaz D, et al. Human $\beta$ cells produce and release serotonin to inhibit glucagon secretion from alpha cells. Cell Rep. 2016;17(12):3281-3291. doi:10.1016/j.celrep.2016.11.072

25. Bennet H, Mollet IG, Balhuizen A, et al. Serotonin (5-HT) receptor $2 \mathrm{~b}$ activation augments glucose-stimulated insulin secretion in human and mouse islets of langerhans. Diabetologia. 2016;59(4):744-754. doi:10.1007/s00125-015-3847-6 
26. Paulmann N, Grohmann M, Voigt JP, et al. Intracellular serotonin modulates insulin secretion from pancreatic $\beta$ cells by protein serotonylation. PLoS Biol. 2009;7(10):e1000229. doi:10.1371/journal. pbio. 1000229

27. Kim H, Toyofuku Y, Lynn FC, et al. Serotonin regulates pancreatic $\beta$ cell mass during pregnancy. Nat Med. 2010;16(7):804-808. doi:10.1038/nm.2173

28. Ohara-Imaizumi M, Kim H, Yoshida M, et al. Serotonin regulates glucose-stimulated insulin secretion from pancreatic $\beta$ cells during pregnancy. Proc Natl Acad Sci. 2013;110(48):19420-19425. doi:10.1073/pnas.1310953110

29. Haahr ME, Hansen DL, Fisher PM, et al. Central 5-HT neurotransmission modulates weight loss following gastric bypass surgery in obese individuals. $J$ Neurosci. 2015;35(14):5884-5889. doi:10.1523/ JNEUROSCI.3348-14.2015

30. Fukui M, Tanaka M, Toda $\mathrm{H}$, et al. High plasma 5-hydroxyindole3 -acetic acid concentrations in subjects with metabolic syndrome. Diabetes Care. 2012;35(1):163-167. doi:10.2337/dc11-1619

31. Li P, Tiwari HK, $\mathrm{Ph} \mathrm{D}$, et al. Genetic association analysis of 30 genes related to obesity in a European American population. Int $J$ Obes. 2014;38(5):724-729. doi:10.1038/ijo.2013.140

32. Opgen-Rhein C, Brandl EJ, Müller DJ, et al. Association of HTR2C, but not LEP or INSIG2, genes with antipsychotic-induced weight gain in a German sample. Pharmacogenomics. 2010;11(6):773-780. doi: $10.2217 /$ pgs. 10.50

33. Chen C, Chen W, Chen C, et al. Genetic variations in the serotoninergic system contribute to body-mass index in Chinese adolescents. PLoS One. 2013;8(3):e58717. doi:10.1371/journal.pone.0058717

34. Kwak SH, Park BL, Kim H, et al. Association of variations in TPH1 and HTR2B with gestational weight gain and measures of obesity. Obesity (Silver Spring). 2012;20(1):233-238. doi:10.1038/ oby. 2011.253

35. Halder I, Muldoon MF, Ferrell RE, Manuck SB. Serotonin receptor 2A (HTR2A) gene polymorphisms are associated with blood pressure, central adiposity, and the metabolic syndrome. Metab Syndr Relat Disord. 2007;5(4):323-330.

36. Corpeleijn E, Petersen L, Holst C, et al. Obesity-related polymorphisms and their associations with the ability to regulate fat oxidation in obese Europeans: the NUGENOB study. Obesity (Silver Spring). 2010;18(7):1369-1377. doi:10.1038/oby.2009.377

37. Ylmaz M, Bayazit YA, Ciftci TU, et al. Association of serotonin transporter gene polymorphism with obstructive sleep apnea syndrome. Laryngoscope. 2005;115(5):832-836. doi:10.1097/01. MLG.0000157334.88700.E6

38. Chen $\mathrm{H}, \mathrm{Hu} \mathrm{K}$, Zhu J, et al. Polymorphisms of the 5-hydroxytryptamine $2 \mathrm{~A} / 2 \mathrm{C}$ receptor genes and 5-hydroxytryptamine transporter gene in Chinese patients with OSAHS. Sleep Breath. 2013;17(4):1241-1248. doi:10.1007/s11325013-0829-0

39. Garvey JF, Pengo MF, Drakatos P, Kent BD. Epidemiological aspects of obstructive sleep apnea. J Thorac Dis. 2015;7(5):920-929. doi:10.3978/j.issn.2072-1439.2015.04.52

40. Heinzer R, Vat S, Marques-Vidal $P$, et al. Prevalence of sleep-disordered breathing in the general population: the HypnoLaus study. Lancet Respir Med. 2015;3:310-318. doi:10.1016/S2213-2600(15)00043-0

41. Young T, Peppard PE, Gottlieb DJ. Epidemiology of obstructive sleep apnea: a population health perspective. Am J Respir Crit Care Med. 2002;165:1217-1239. doi:10.1164/rccm.2109080

42. Knutson KL, Ryden AM, Mander BA, Van Cauter E. Role of sleep duration and quality in the risk and severity of type 2 diabetes mellitus. Arch Intern Med. 2006;166(16):1768-1774. doi:10.1001/ archinte.166.16.1768

43. Gangwisch JE, Heymsfield SB, Boden-Albala B, et al. Sleep duration as a risk factor for diabetes incidence in a large U.S. sample. Sleep. 2007;30(12):1667-1673. doi:10.1093/sleep/30.12.1667
44. Peppard PE, Young T, Palta M, Dempsey J, Skatrud J. Longitudinal study of moderate weight change and sleep-disordered breathing. JAMA. 2000;284(23):3015-3021. doi:10.1001/jama.284.23.3015

45. van de Wall E, Leshan $\mathrm{R}, \mathrm{Xu} \mathrm{AW}$, et al. Collective and individual functions of leptin receptor modulated neurons controlling metabolism and ingestion. Endocrinology. 2008;149:1773-1785. doi:10.1210/en.2007-1132

46. Kenny PJ. Reward mechanisms in obesity: new insights and future directions. Neuron. 2011;69:664-679. doi:10.1016/j. neuron.2011.02.016

47. Sakowski SA, Geddes TJ, Thomas DM, Levi E, Hatfield JS, Kuhn DM. Differential tissue distribution of tryptophan hydroxylase isoforms 1 and 2 as revealed with monospecific antibodies. Brain Res. 2006;1085:11-18. doi:10.1016/j.brainres.2006.02.047

48. Lesurtel M, Graf R, Aleil B, et al. Platelet-derived serotonin mediates liver regeneration. Science. 2006;312(5770):104-107. doi:10.1126/ science. 1123842

49. Sengupta A, Weljie AM. Metabolism of sleep and aging: bridging the gap using metabolomics. Nutr Health Aging. 2019;5(3):167-184. doi:10.3233/NHA-180043

50. Schwartz JR, Roth T. Neurophysiology of sleep and wakefulness: basic science and clinical implications. Curr Neuropharmacol. 2008;6(4):367-378.

51. Koskela AK, Kaurijoki S, Pietilainen KH, et al. Serotonin transporter binding and acquired obesity - an imaging study of monozygotic twin pairs. Physiol Behav. 2008;93:724-732.

52. Kim DC, Jun DW, Il KY, et al. 5-HT2A receptor antagonists inhibit hepatic stellate cell activation and facilitate apoptosis. Liver Int. 2013;33(4):535-543. doi:10.1111/liv.12110

53. Takahashi T, Yano M, Minami J, et al. Sarpogrelate hydrochloride, a serotonin2A receptor antagonist, reduces albuminuria in diabetic patients with early-stage diabetic nephropathy. Diabetes Res Clin Pract. 2002;58(2):123-129. doi:10.1016/S0168-8227(02)00105-5

54. Bertrand PP, Bertrand RL. Serotonin release and uptake in the gastrointestinal tract. Auton Neurosci. 2010;153(1-2):47-57. doi:10.1016/j. autneu.2009.08.002

55. Kwon O, Yu JH, Jeong E, Yoo HJ, Kim MS. Meal-related oscillations in the serum serotonin levels in healthy young men. Clin Endocrinol (Oxf). 2018;88(4):549-555. doi:10.1111/cen.13545

56. Subramani Y, Singh M, Wong J, Kushida CA, Malhotra A, Chung F. Understanding phenotypes of obstructive sleep apnea: applications in anesthesia, surgery, and perioperative medicine. Anesth Analg. 2017;124(1):179-191. doi:10.1213/ANE.0000000000001546

57. Bonsignore MR, Baiamonte P, Mazzuca E, Castrogiovanni A, Marrone O. Obstructive sleep apnea and comorbidities: a dangerous liaison. Multidiscip Respir Med. 2019;14:8. doi:10.1186/s40248-0190172-9

58. Fleury Curado T, Fishbein K, Pho H, et al. Chemogenetic stimulation of the hypoglossal neurons improves upper airway patency. Sci Rep. 2017;7:44392. doi:10.1038/srep44392

59. Hukins CA. Obstructive sleep apnea - management update. Neuropsychiatr Dis Treat. 2006;2(3):309-326. doi:10.2147/ nedt.2006.2.3.309

60. Rosmond R, Bouchard C, Björntorp P. Increased abdominal obesity in subjects with a mutation in the 5-HT 2A receptor. Ann N Y Acad Sci. 2002;967:571-575. doi:10.1111/j.1749-6632.2002.tb04319.x

61. Lent CM, Fliegner KH, Freedman E, Dickinson MH. IngestiveBehaviour and physiology of the medicinal leech. $J$ Exp Biol. 1988;137:513-527.

62. Popa D, Léna C, Fabre V, et al. Contribution of 5-HT2 receptor subtypes to sleep-wakefulness and respiratory control, and functional adaptations in knock-out mice lacking 5-HT2A receptors. J Neurosci. 2005;25:11231e8. doi:10.1523/JNEUROSCI.1724-05.2005

63. Ahuja S, Chen RK, Kam K, Pettibone WD, Osorio RS, Varga AW. Role of normal sleep and sleep apnea in human memory processing. Nat Sci Sleep. 2018;10:255-269. doi:10.2147/NSS.S125299 
64. Buchanan GF, Richerson GB. Central serotonin neurons are required for arousal to CO2. Proc Natl Acad Sci U S A. 2010;107 (37):16354-16359. doi:10.1073/pnas.1004587107

65. Buchanan GF, Smith HR, MacAskill A, Richerson GB. 5-HT2A receptor activation is necessary for $\mathrm{CO} 2$-induced arousal. $J$ Neurophysiol. 2015;114(1):233-243. doi:10.1152/jn.00213.2015

66. Nakano H, Magalang UJ, Lee SD, Krasney JA, Farkas GA. Serotonergic modulation of ventilation and upper airway stability in obese zucker rats. Am J Respir Crit Care Med. 2001;163 (5):1191-1197. doi:10.1164/ajrccm.163.5.2004230

67. Veasey SC, Panckeri KA, Hoffman EA, Pack AI, Hendricks JC. The effects of serotonin antagonists in an animal model of sleep-disordered breathing. Am J Respir Crit Care Med. 1996;153 (2):776-786. doi:10.1164/ajrccm.153.2.8564132

68. Ancoli-Israel S, Kripke DF, Klauber MR, Mason WJ, Fell R, Kaplan O. Sleep-disordered breathing in community-dwelling elderly. Sleep. 1991;14(6):486-495. doi:10.1093/sleep/14.6.486

69. Reynolds CF, Kupfer DJ, McEachran AB, Taska LS, Sewitch DE, Coble PA. Depressive psychopathology in male sleep apneics. J Clin Psychiatry. 1984;45(7):287-290.

70. Ohayon MM. The effects of breathing-related sleep disorders on mood disturbances in the general population. $J$ Clin Psychiatry. 2003;64(10):1195-1200. doi:10.4088/JCP.v64n1009

71. Pan ML, Tsao HM, Hsu CC, et al. Bidirectional association between obstructive sleep apnea and depression: a population-based longitudinal study. Medicine (Baltimore). 2016;95(37):e4833. doi:10.1097/ MD.0000000000004833

72. Nixon GM, Brouillette RT. Sleep and breathing in prader-willi syndrome. Pediatr Pulmonol. 2002;34(3):209-217.

73. Ozbek E, Otunctemur A, Simsek A, et al. Genetic polymorphism in the serotonin transporter gene-linked polymorphic region and response to serotonin reuptake inhibitors in patients with premature ejaculation. Clinics. 2014;69:710-713. doi:10.6061/clinics/2014(11) 01
74. Lesch KP, Balling U, Gross J, et al. Organization of the human serotonin transporter gene. J Neural Transm Gen Sect. 1994;95 (2):157-162. doi:10.1007/BF01276434

75. Kunugi H, Hattori M, Kato $\mathrm{T}$, et al. Serotonin transporter gene polymorphisms: ethnic difference and possible association with bipolar affective disorder. Mol Psychiatry. 1997;2(6):457-462. doi:10.1038/sj.mp.4000334

76. De Geus EJC, Posthuma D, Kupper N, et al. A whole genome scan for 24-hour respiration rate: a major locus at 10q26 influences respiration during sleep. Am J Hum Genet. 2005;76:100-111. doi:10.1086/427267

77. Sookoian S, Gemma C, Gianotti TF, et al. Serotonin and serotonin transporter gene variant in rotating shift workers. Sleep. 2007;30 (8):1049-1053. doi:10.1093/sleep/30.8.1049

78. Schröder CM, Primeau MM, Hallmayer JF, Lazzeroni LC, Hubbard JT, O'Hara R. Serotonin transporter polymorphism is associated with increased apnea-hypopnea index in older adults. Int J Geriatr Psychiatry. 2013;29(3):227-235. doi:10.1002/gps.3994

79. Lucki I. The spectrum of behaviors influenced by serotonin. Biol Psychiatry. 1994;44(3):151-162. doi:10.1016/S0006-3223(98) 00139-5

80. Carleij DW, Rachilovacki M. Role of peripheral serotonin in the regulation of central sleep apneas in rats. Chest. 1999;115 (5):1397-1401. doi:10.1378/chest.115.5.1397

81. Tripathi A, Bagchi S, Singh J, Tripathi S, Gupta NK, Arora V. Incidence of obstructive sleep apnea in elderly edentulous patients and the possible correlation of serum serotonin and apnea-hypopnea index. J Prosthodont. 2019;28(2):e843-e848. doi:10.1111/jopr.12654

82. Brummett BH, Krystal AD, Ashley-Koch A, et al. Sleep quality varies as a function of 5-HTTLPR genotype and stress. Psychosom Med. 2007;69(7):621-624. doi:10.1097/PSY.0b013e31814b8de6

83. Deuschle M, Schredl M, Schilling C, et al. Association between a serotonin transporter length polymorphism and primary insomnia. Sleep. 2010;33(3):343-347. doi:10.1093/sleep/33.3.343

\section{Publish your work in this journal}

Nature and Science of Sleep is an international, peer-reviewed, open access journal covering all aspects of sleep science and sleep medicine, including the neurophysiology and functions of sleep, the genetics of sleep, sleep and society, biological rhythms, dreaming, sleep disorders and therapy, and strategies to optimize healthy sleep.
The manuscript management system is completely online and includes a very quick and fair peer-review system, which is all easy to use. Visit http://www.dovepress.com/testimonials.php to read real quotes from published authors. 